\title{
Diffuse swelling of the buccal mucosa and palate as first and only manifestation of an extranodal non-Hodgkin 'double-hit' lymphoma: report of a case
}

\author{
Marc Frei • Patrick Dubach • Peter A. Reichart • \\ Anja M. Schmitt • Esther Mueller-Garamvölgyi • \\ Michael M. Bornstein
}

Received: 19 August 2010 / Accepted: 13 October 2010 /Published online: 28 October 2010

(C) Springer-Verlag 2010

\begin{abstract}
Background Most of the lymphomas arising in the oral cavity are of B-cell origin. Among these, diffuse large Bcell lymphomas are the most common. Diffuse large B-cell lymphomas may exhibit more than one chromosomal rearrangement and are then referred to as 'double-hit' or 'triple-hit' lymphomas.

Case report We present a case of an intraoral 'double-hit' lymphoma in a 76-year-old male who had been referred by an oral surgeon in private practice. Intraoral examination exhibited a firm, exophytic lesion in the region of the right hard palate and buccal mucosa with extension to the soft palate. Radiographic examination exhibited a massive thickening of the right sinus membrane, and arrosion of the lateral and basal cortical sinus walls in the right maxilla. After diagnosis of the lesion, the patient was treated with six cycles of chemotherapy.

Discussion Lymphomas arising within the oral cavity account for less than $5 \%$ of all oral malignancies and typically affect the palatine tonsils and the palate. 'Double-hit'
\end{abstract}

M. Frei · P. A. Reichart · M. M. Bornstein $(\bowtie)$

Department of Oral Surgery and Stomatology,

School of Dental Medicine, University of Bern,

Freiburgstrasse 7,

3010 Bern, Switzerland

e-mail: michael.bornstein@zmk.unibe.ch

P. Dubach

Department of ENT, Head and Neck Surgery, Inselspital,

University of Bern,

Bern, Switzerland

A. M. Schmitt • E. Mueller-Garamvölgyi

Department of Pathology, University of Bern,

Bern, Switzerland lymphomas are associated with older age, usually present with an advanced stage of disease, and show an aggressive clinical behaviour. They normally have a poor prognosis, even when treated with intensive chemotherapy regimens. Nevertheless, in the case presented, the patient was free of symptoms 1 year after initial diagnosis.

Keywords Non-Hodgkin lymphoma · Diffuse large B-cell lymphoma · 'Double-hit' lymphoma - 'B-cell lymphoma, unclassifiable, with features between diffuse large B-cell lymphoma and Burkitt lymphoma' - Oropharyngeal lymphomas

\section{Introduction}

Lymphomas are a heterogeneous group of malignant neoplasms of lymphocytes and their precursor cells. They are traditionally subdivided into Hodgkin's lymphomas and non-Hodgkin lymphomas according to their histology and patterns of behaviour. Hodgkin's lymphoma is histologically characterised by the presence of Hodgkin- and Reed-Sternberg cells, and clinically often presents as nodal disease, with a predilection for neck and mediastinal lymph nodes. All other neoplasms of the lymphoid system are called non-Hodgkin lymphomas (NHLs) and are further subdivided according to the World Health Organisation (WHO) classification of haematopoietic and lymphoid neoplasms [1].

In contrast to Hodgkin's lymphoma, NHLs have a propensity to disseminate to extranodal locations. These tissues are quite diverse in type and region, including stomach, skin, lung, central nervous system, orbit, salivary glands and the oral cavity [2]. Up to $40 \%$ of NHL present at 
an extranodal site [3], with $2 \%$ to $3 \%$ of these extranodal NHL cases first arising in the oral mucosa and jaws [2, 4].

Oropharyngeal lymphomas are the second most common malignant disease in the oral region, after squamous cell carcinoma [5], and the most frequent non-epithelial malignant neoplasia in the maxillofacial region [6]. They generally occur in the Waldeyer's tonsillar ring (pharyngeal tonsil or tubal tonsil). Lymphomas arising within the oral cavity account for less than $5 \%$ of all oral malignancies $[5,7]$ and typically affect the palatine tonsils and the palate [7-9]. To the best of our knowledge, the following case presentation describes and discusses the first manifestation of an intraoral 'double-hit' lymphoma, an entity in which a diffuse large B-cell lymphoma exhibits two distinct chromosomal rearrangements.

\section{Case report}

The patient, a 76-year-old male who had been a pipe smoker for 22 years, was referred to the Department of Oral Surgery and Stomatology by an oral surgeon in private practice. The patient had been referred to the oral surgeon by the nursing home staff. During the last few months, swelling of the right buccal plane and palate had developed, and the patient had started to complain because his upper denture did not fit anymore. His medical history included several cardiovascular risk factors: hypertensive cardiopathy, insulin-independent diabetes mellitus with renal insufficiency, and obesity.

At the initial examination, the patient was afebrile, without any palpable lymph nodes in the head and neck region, and he did not mention any recent weight loss. He reported only a little pain when the tumour was pressed. Clinically, the right side of his face was slightly asymmetric and swollen. Intraoral examination exhibited a firm, exophytic lesion in the region of the right hard palate and buccal mucosa, with extension to the soft palate. The mucosal surface of the mass was slightly red but not particularly noticeable (Fig. 1). Hypoesthesia in the second branch of the trigeminal nerve was recorded. Surprisingly, the full upper denture had been shaped and adapted around the tumour (Fig. 2). The patient reported that he had visited a dental technician after the swelling had become established because of mismatch and pain due to the upper denture.

Limited cone beam computed tomography (CBCT; field of view $=6 \times 6 \mathrm{~cm}$; $3 \mathrm{D}$ Accuitomo XYZ Slice View Tomograph, J. Morita) was performed to detect potential destruction of the underlying maxillary bone in the area. In the corresponding CBCT slices, a massive thickening of the right sinus membrane could be observed. The images also showed arrosion of the lateral and basal cortical sinus walls in the right maxilla (Fig. 3).

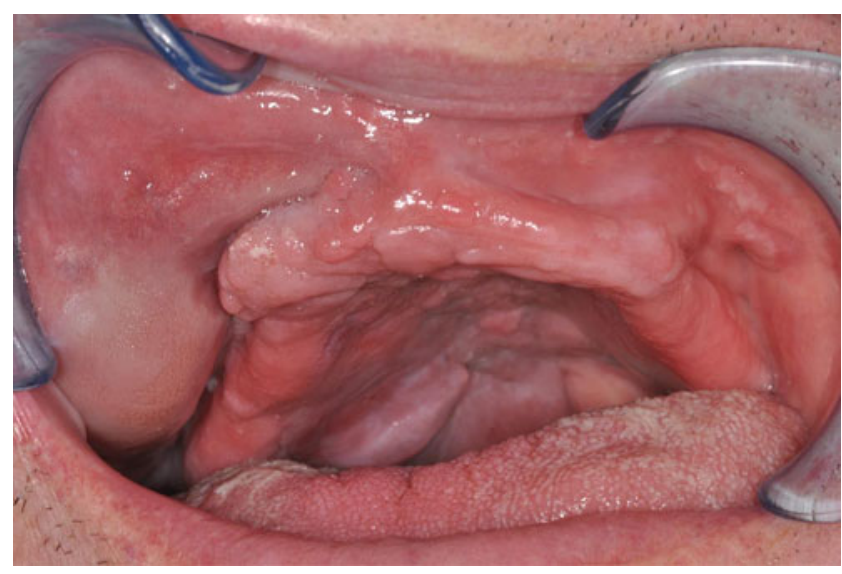

Fig. 1 Initial clinical aspect of the exophytic, painless mass in the region of the right hard palate and buccal mucosa

Based on these clinical and radiographic findings, a malignant process was suspected. Therefore, the patient was immediately referred to the interdisciplinary tumour board of the Department of ENT, Head and Neck Surgery at the University Hospital of Bern for further diagnostic procedures. A computed tomography (CT) scan was performed, and the patient was hospitalised. A biopsy of the tumorous mass on the buccal mucosa was taken, and endoscopy of all paranasal sinuses was performed.

The histopathologic examination (Fig. 4a, b) of the biopsy showed massive infiltrates of blast-like lymphoid cells with high proliferative activity (90\%) invading the skeletal muscle. The tumour cells demonstrated the characteristic morphology of B-blasts, with large, irregularly contoured nuclei with mostly one centrally placed nucleolus (Fig. 4c, d). No starry-sky pattern, as observed in Burkitt lymphoma, could be detected. The immunohistochemical analysis revealed a positive reaction for the B-cell markers CD20, CD79a and Pax-5 and co-expression of CD10 and BCL-2 (from B-cell lymphoma 2, the second

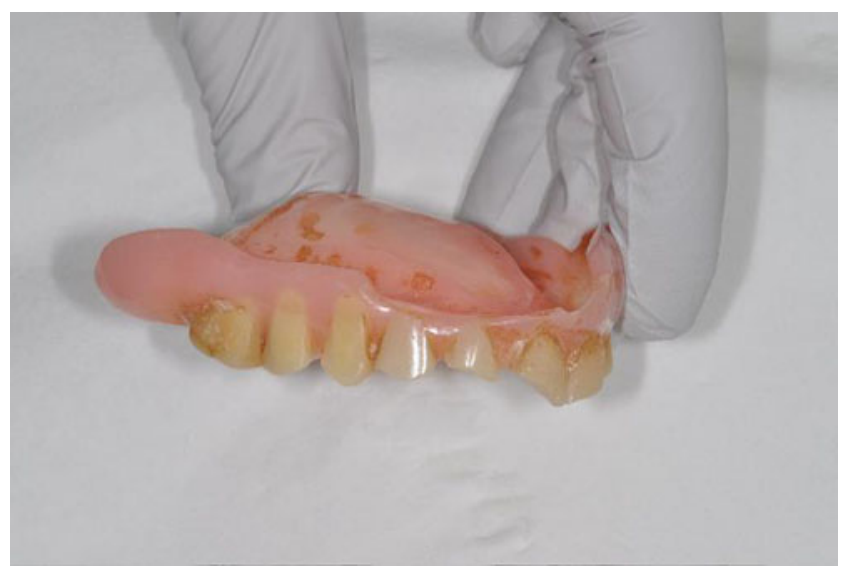

Fig. 2 Right aspect of the denture with clearly reduced margins due to the tumorous mass 
Fig. 3 Coronal (a, b), sagittal (c) and horizontal (d) CBCT slices depict swelling in the right maxillary sinus and erosion of the lateral cortical sinus wall
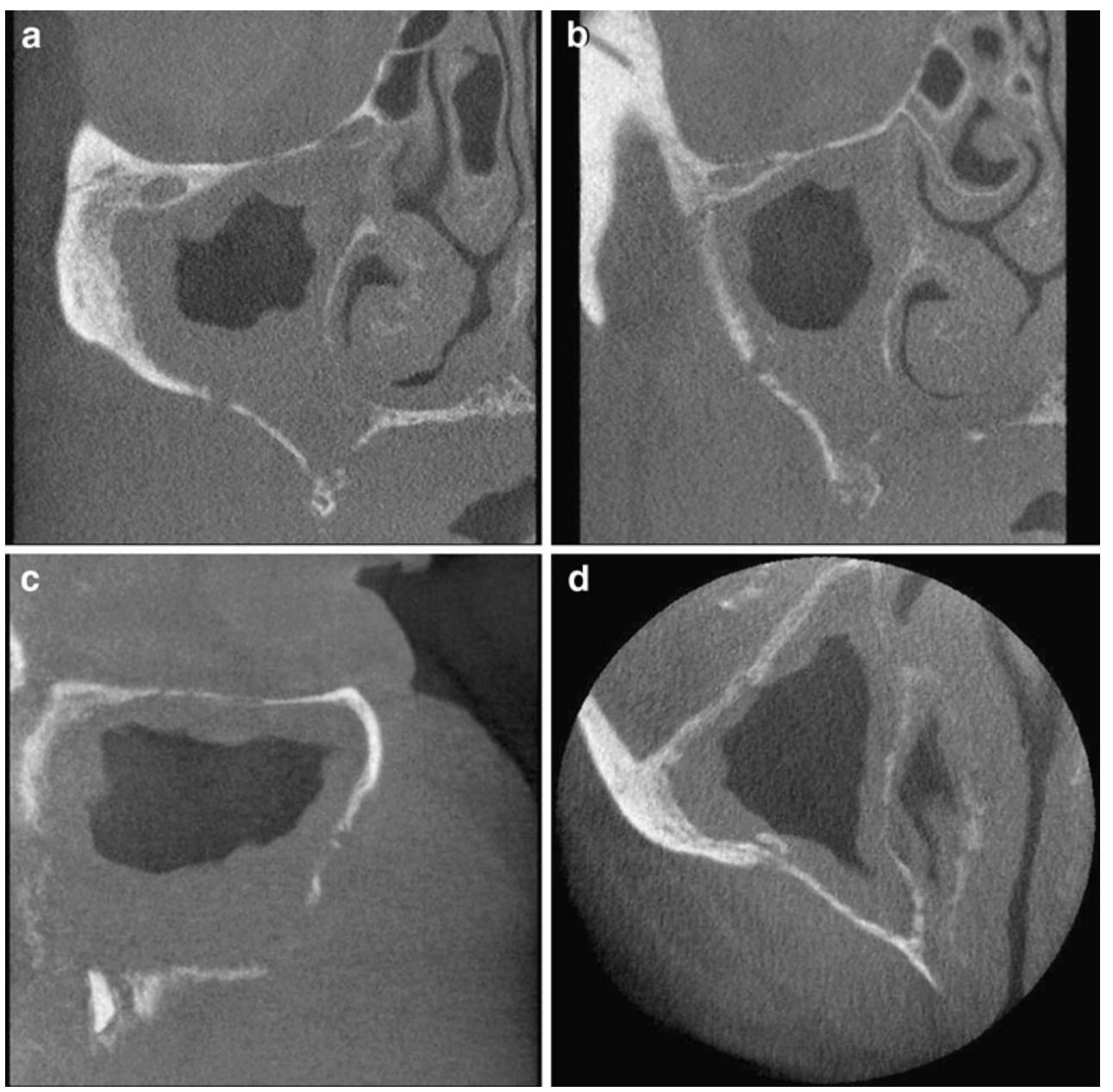

member of a range of proteins initially described in follicular lymphomas that play a role in decreased apoptosis), while there was only a weak positivity for BCL-6. The tumour cells did not stain for MUM-1. Due to the high proliferative index, the positivity for BCL-6 and CD10, and the negativity for MUM-1, the possibility of a 'double-hit' was considered and the probe underwent further analyses. In a fluorescence in situ hybridisation (FISH), breaks at the BCL-6 and cMYC loci, but not the BCL-2 locus, were detected. Thus, the tumour was classified as a 'double-hit' diffuse large B-cell lymphoma. The complete staging revealed a stage IIIA with infiltration of the upper pole of the right kidney. The patient then received six cycles of RCHOP chemotherapy, a combination of a $\mathrm{CHOP}$ regimen (cyclophosphamide, hydroxydaunorubicin, oncovin and prednisone) with the monoclonal CD20-antibody rituximab. He received one cycle every 3 weeks. After four cycles, a CT scan was taken, showing complete remission of the tumour. A residual facial nerve palsy on the right side was noticed. In the hard palate, a soft tissue lesion with exposure of underlying bone was visible (Fig. 5). Because of the total absence of symptoms, no surgical revision was initiated, and the patient was instructed in the use of a chlorhexidine gel for local disinfection of the wound region. One year following initial diagnosis, the patient remains in our care, with visits scheduled every 4 to 6 months.

\section{Discussion}

Extranodal NHLs can affect patients of all ages, but the peak incidence is between 60 and 70 years of age. The NHLs show a predilection for the maxilla, including the soft tissues of the palate. No gender predilection can be observed in affected patients [10, 11]. NHLs can be grouped in subtypes based on their histologic pattern, cellular morphology and immunohistochemical staining. The WHO classification of haematopoietic and lymphoid neoplasms aims at combining the clinical aspects, histomorphological features, immunohistochemical phenotype and genetic features [1]. The aggressive diffuse large B-cell lymphoma (DLBCL) is reported to account for $50 \%$ to $68 \%$ of all non-Hodgkin lymphomas [12]. The 5-year overall 

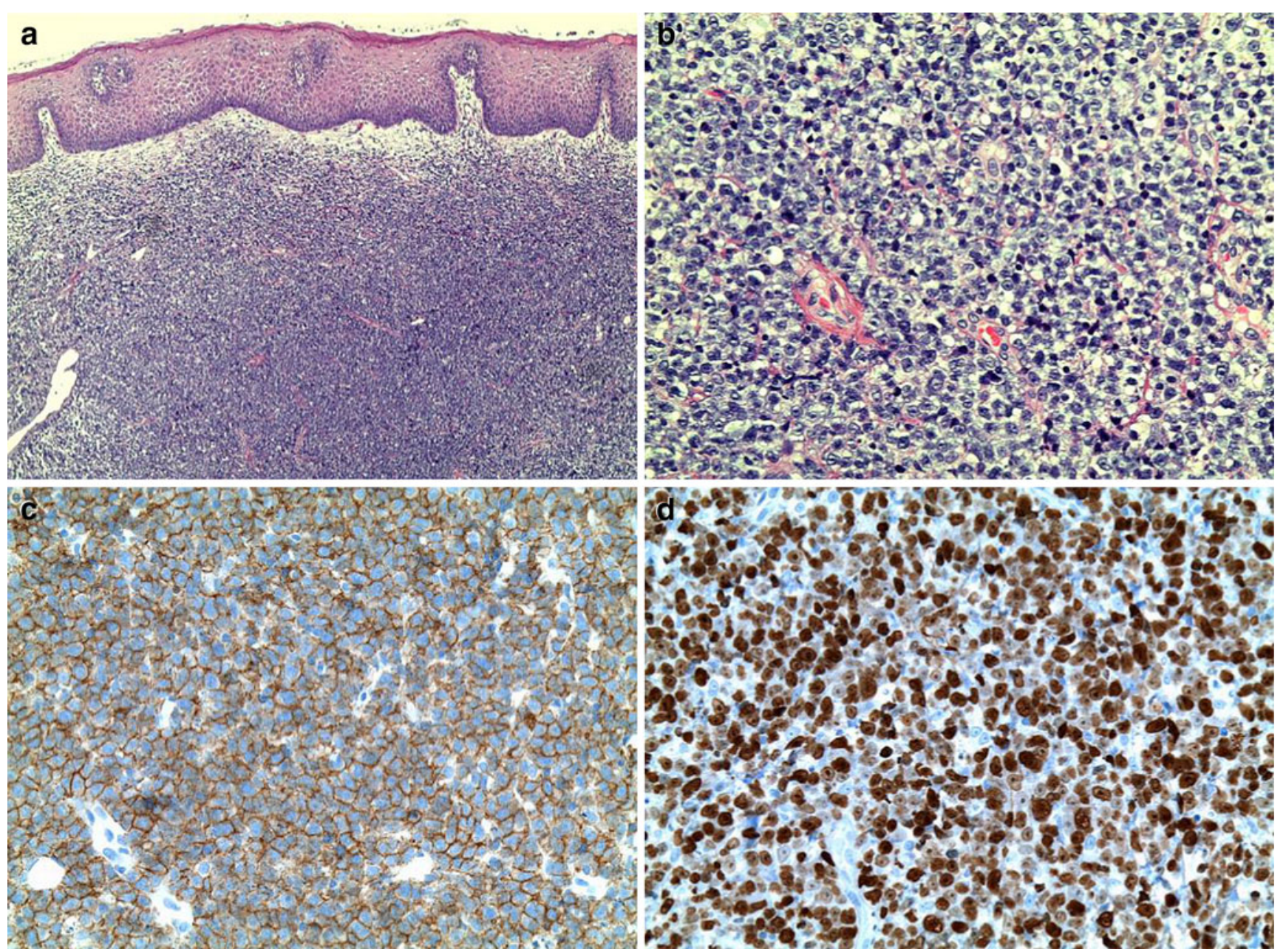

Fig. 4 Incisional biopsy of the tumourous mass. a Overview of the lesion, with squamous epithelium covering the lymphoma infiltrates. b Proliferation of blasts at a higher magnification. Note the classic blastic appearance of the neoplastic cells, with round and vesicular

nuclei and mostly one centrally placed nucleolus. c Immunostaining for CD20. All neoplastic cells show a strong membranous staining pattern for CD20. d Immunostaining for Mib-1. The proliferation index is about $90 \%$

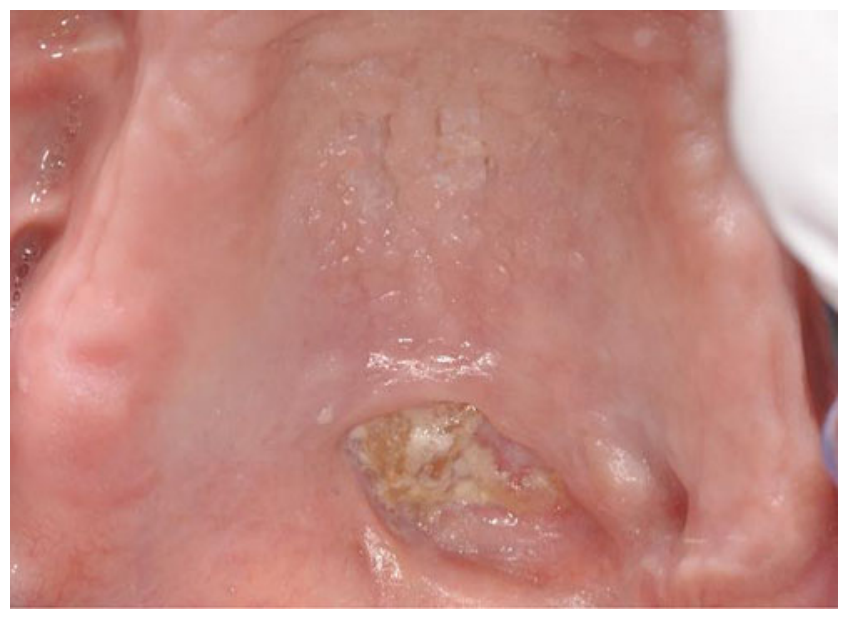

Fig. 5 Residual soft tissue lesion with exposure of underlying bone in the palate survival rate depends on the stage of the tumour at diagnosis, and is reported to be around 50\% [13]. Therefore, early diagnosis is imperative.

Regarding the reduced margins of the denture in the case presented, the tumour mass seems to have been present and growing for quite some time before diagnosis. It can be speculated that the NHL could have been diagnosed earlier if the patient had visited a dentist instead of a dental technician [14]. In the present case, it was not possible to exactly determine the delay in diagnosis, as the patient could not remember when he initially went to see the dental technician or how often he returned. This case report illustrates the necessity of regular screening of edentulous patients by a trained dentist. However, case reports like this seem to be rare [15].

Patients with intraoral lymphoma often present with nonspecific radiological and clinical signs such as obstruction of paranasal sinuses in radiographic images and swelling or 
ulceration of the mucosa. Initially, the lesions are often mistaken for inflammatory or reactive processes. As differential diagnoses, squamous cell carcinoma and benign or malignant neoplasias of palatal salivary glands should also be excluded, ideally with an incisional biopsy [16].

The most common chromosomal rearrangement in diffuse large B-cell lymphoma is the BCL-6 translocation (up to $30 \%$ ), followed by BCL-2 rearrangements (20-30\%) and MYC rearrangements (up to 10\%). So-called double-hit lymphomas exhibit two chromosomal rearrangements [17]. Based on morphological, immunohistochemical and genetic findings, these tumours can be classified as 'double-hit' diffuse large B-cell lymphomas or as 'B-cell lymphoma, unclassifiable, with features between diffuse large B-cell lymphoma and Burkitt lymphoma'. The latter entity was introduced by the 2008 WHO Classification of Tumors of Haematopoietic and Lymphoid Tissues together with another new entity called 'B-cell lymphoma, unclassifiable, with features between diffuse large B-cell lymphoma and classical Hodgkin lymphoma' $[18,19]$. These lymphomas are also referred to as 'grey-zone lymphomas'. In the present case, the differential diagnosis of a 'B-cell lymphoma, unclassifiable, with features intermediate between diffuse large B-cell lymphoma and Burkitt lymphoma' was considered. However, the typical morphology of the blasts, the strong positivity for BCL-2 and the only weak positivity for BCL-6 were in favour of the diagnosis of a 'double-hit' diffuse large B-cell lymphoma.

'Double-hit' lymphomas involving a rearrangement of both the MYC and the BCL-6 gene loci show a more aggressive clinical behaviour and usually present with an advanced stage of disease. They normally have a poor prognosis, even when treated with intensive chemotherapy regimens [20,21]. The reason for the aggressive behaviour is the overexpression of pro-proliferative (MYC) and anti-apoptotic (BCL2, BCL6) oncoproteins at the same time. To the best of our knowledge, this case presented describes and discusses the first manifestation of an intraoral double-hit lymphoma.

\section{Conclusion}

The present case report of diffuse swelling of the buccal mucosa and palate as the first and only manifestation of an extranodal non-Hodgkin 'double-hit' lymphoma in a 76-yearold patient shows the need for immediate and accurate diagnostic procedures, including immunohistochemical analysis, to avoid delay and inappropriate treatment strategies.

Conflict of interest There are no financial relationships between any author and a commercial company that may pose a conflict of interest.

\section{References}

1. Swerdlow S, Campo E, Harris NL, Jaffe ES, Pileri SA, Stein H, Thiele J, Vardiman JW (2008) WHO classification of tumors of hematopoietic and lymphoid tissues. IARC, Lyon

2. Otter R, Gerrits WBJ, van der Sandt MM, Hermanns J, Willemze R (1989) Primary extranodal and nodal non-Hodgkin's lymphoma. A survey of a population-based registry. Eur J Cancer Clin Oncol 25:1203-1210

3. Jordan RX, Speight PM (1996) Extranodal non-Hodgkin's lymphomas of the oral cavity. Curr Top Pathol 90:125-146

4. Freeman C, Berg JW, Cutler SJ (1972) Occurrence and prognosis of extranodal lymphomas. Cancer 29:252-260

5. Epstein JB, Epstein JD, Le N, Gorsky M (2001) Characteristics of oral and paraoral malignant lymphoma: a population-based review of 361 cases. Oral Surg Oral Med Oral Pathol Oral Radiol Endo 92:519-525

6. Shihdoh M, Takami T, Arisue M et al (1997) Comparison between submucosal (extra-nodal) and nodal non-Hodgkin's lymphoma (NHL) in the oral and maxillofacial region. J Oral Pathol Med 26:283-289

7. Eisenbud L, Sciubba J, Mir R, Sachs SA (1983) Oral presentations in non-Hodgkin's lymphoma: a review of 31 cases. Part I. Data analysis. Oral Surg Oral Med Oral Pathol 56:151-156

8. Werder P, Altermatt HJ, Zbären P, Mueller-Garamvolgyi E, Bornstein MM (2010) Palatal swelling as the first and only manifestation of extranodal follicular non-Hodgkin lymphoma: a case presentation. Quintessence Int 41:93-97

9. Kolokotronis A, Konstantinou N, Christakis I, Papadimitriou P, Matiakis A, Zaraboukas T, Antoniades D (2005) Localized B-cell non-Hodgkin's lymphoma of oral cavity and maxillofacial region: a clinical study. Oral Surg Oral Med Oral Pathol Oral Radiol Endo 99:303-310

10. Urquhart A, Berg R (2001) Hodgkin's and non-Hodgkin's lymphoma of the head and neck. Laryngoscope 111:1565-1569

11. van der Waal RI, Huijgens PC, van der Valk P, van der Waal I (2005) Characteristics of 40 primary extranodal non-Hodgkin lymphomas of the oral cavity in perspective of the new WHO classification and the international prognostic index. Int $\mathrm{J}$ Oral Maxillofac Surg 34:391-395

12. Kemp S, Gallagher G, Kabani S, Noonan V, O’Hara C (2008) Oral non-Hodgkin's lymphoma: review of the literature and World Health Organization classification with reference to 40 cases. Oral Surg Oral Med Oral Pathol Oral Radiol Endo 105:194-201

13. Authors V (1997) A clinical evaluation of the International Lymphoma Study Group classification on non-Hodgkin's lymphoma. The Non-Hodgkin's Lymphoma Classification Project. Blood 89:3909-3918

14. Holmes JD, Dierks EJ, Homer LD, Potter BE (2003) Is detection of oral and oropharyngeal squamous cancer by a dental health care provider associated with a lower stage at diagnosis? J Oral Maxillofac Surg 61:285-291

15. George GS, Welfare RD, Lund VJ (2005) An undiagnosed case of malignancy: case report. Br Dent J 198:341-343

16. Werder P, Altermatt HJ, Zbären P, Bornstein MM (2009) Canalicular adenoma of a minor salivary gland on the palate: a case presentation. Quintessence Int 40:623-626

17. Stein H, Warnke RA, Chan WC, Jaffe ES, Chan JKC, Gatter KC, Campo E (2008) Diffuse large B-cell lymphoma, not otherwise specified. In: Swerdlow S, Campo E, Harris NL, Jaffe ES, Pileri SA, Stein H, Thiele J, Vardiman JW (eds) WHO classification of tumors of hematopoietic and lymphoid tissues. IARC, Lyon, pp 233-237

18. Kluin PM, Harris NL, Stein H, Leoncini L, Raphaël M, Campo E, Jaffe ES (2008) B-cell lymphoma, unclassifiable, with features intermediate between diffuse large B-cell lymphoma and Burkitt lymphoma. In: Swerdlow S, Campo E, Harris NL, Jaffe ES, Pileri SA, 
Stein H, Thiele J, Vardiman JW (eds) WHO classification of tumors of hematopoietic and lymphoid tissues. IARC, Lyon, pp 265-266

19. Jaffe ES, Stein H, Swerdlow SH, Campo E, Pileri SA, Harris NL (2008) B-cell lymphoma, unclassifiable, with features intermediate between diffuse large B-cell lymphoma and classical Hodgkin lymphoma. In: Swerdlow S, Campo E, Harris NL, Jaffe ES, Pileri SA, Stein H, Thiele J, Vardiman JW (eds) WHO Classification of tumors of hematopoietic and lymphoid tissues. IARC, Lyon, pp 267-268
20. Hasserjian RP, Ott G, Elenitoba-Johnson KSJ, Balague-Ponz O, de Jong D, de Leval L (2009) Commentary on the WHO classification of tumors of lymphoid tissues (2008): "gray zone" lymphomas overlapping with Burkitt lymphoma or classical Hodgkin lymphoma. J Hematopathol 2:89-95

21. Kolman OK, Snuderl M, Ferry JA, Hochberg EP, Chen YB, Hasserjian RP, Rahemtullah A (2008) Clinicopathologic features of B-cell lymphomas with concurrent BCL-2 and c-MYC gene rearrangements. Mod Pathol 21(Suppl 1):260A 